

\section{Artigo Especial}

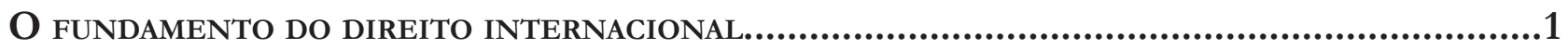
Alfred Verdross

\section{Proteção Internacional dos Direitos Humanos}

INDIGENOUS RIGHTS MOVEMENT: IS THE SAME NEEDED TO PREVENT CONTINUED HUMAN RIGHTS VIOLATIONS OF THE MENTALLY ILL

Liesel LeCates

O Discurso DAS DROGAS CONSTRUído PELO DIREITO INTERNACIONAL

Camila Soares Lippi

O ESTADO DEMOCRÁTICO DE DIREITO LAICO E A "NEUTRALIDADE" ANTE A INTOLERÂNCIA RELIGIOSA

Antonio Baptista Gonçalves

UM DiREITO SEM ESTADO? DiREITOS humanos E A FORMAÇÃo DE UM NOVO QUADRo NORMATIVO GLOBAL .87

Anderson Vichinkeski Teixeira e Rafael Köche

\section{Direito Humanitário}

The U.N. Standard Minimum Rules for the Treatment of Prisoners and North Korea: How North Korea is Violating these Rules with its Operation of the Yodok Concentration CAMP.

Tom Theodore Papain

U.S. Institutionalized Torture with Impunity: Examining Rape and Sexual Abuse in Custody Through the ICTY JurisprudenCE. 126 Allison Rogne 
Abduction, Torture, Interrogation: An Argument Against Extraordinary RendiTION

Kaitlyn E. Tucker

United States and European Union approaches to the death penalty: America SHOULD CONSIDER A NEW PERSPECTIVE 155 Katie R Hill

Tudo DE NOVO NO FRONT: MONUSCO, UMA NOVA ERA NAS PEACEKEEPING OPERATIONS? .169 Priscila Fett

A ADMINISTRAÇÃo DE TERRITÓRIOS OCUPADOS: INDETERMINAÇÃO DAS NORMAS DE DIREITO INTERNACIONAL HUMANITÁRIO?. 184 João Henrique Ribeiro Roriz, Fabia Fernandes Carvalho Veçoso e Lucas da Silva Tasquetto

THE (IN)APPLICABILITY OF THE STATUTE OF REFUGEES TO ENVIRONMENTALLY DISPLACED PERSONS 197 Maria Cláudia da Silva Antunes de Souza e Lucas de Melo Prado

\section{Sistema Interamericano de Direitos Humanos}

A contribuição da Comissão Interamericana de Direitos Humanos para o acesso À jus-

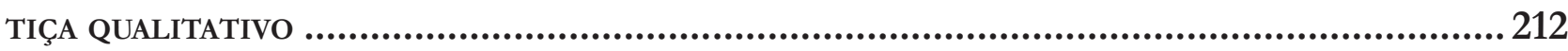
Márcio Antônio de Oliveira Filho, Ana Caroline Portes de Oliveira, Jéssica Galvão Chaves e Warlen Soares Teodoro

A executividade das sentenças da Corte Interamericana de Direitos Humanos no

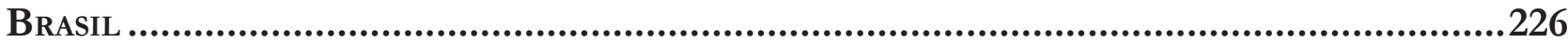

Augusto César Leite de Resende

A efetividade do ativismo jurídico transnacional no Sistema Interamericano de DiREITOS HuMANOS: UMA ANÁLISE A PARTIR DE CASOS CONTRA O BRASIL .................................238 Renata Mantovani de Lima e Lucélia de Sena Alves

O Processo e o Direito Coletivo no Sistema Interamericano de Direitos Humanos: UMA ANÁLISE COM BASE NA JURISPRUDÊNCIA INTERNACIONAL ...........................................250 Laercio Dias Franco Neto e Dafne Fernandez de Bastos 
CORTE INTERAMERICANA DE DIREITOS HUMANOS: OPINIÃo CONSULTIVA 4/84 - A MARGEM DE

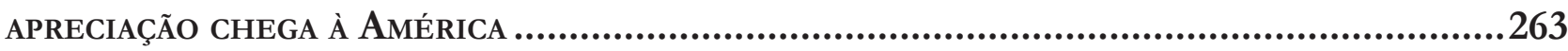

Paloma Morais Corrêa

A "PLENA" LIBERDADE DE EXPRESSÃo E OS DIREITOS HUMANOS: ANÁLISE DA JURISPRUDÊNCIA DA Corte InTeramericana de Direitos Humanos e o Julgamento da ADPF 130 281 Natália Paes Leme Machado

A proteção do meio ambiente no Sistema Interamericano de Direitos Humanos a parTIR DO DIREITO À EDUCAÇÃO.

Augusto César Leite de Resende

Parameters and procedures of the Inter-American System of Human Rights in CHILDREN'S RIGHTS VIOLATION LAWSUITS

Maria Guiomar da Cunha Frota e Pedro Alves Barbosa Neto

Poverty as a Violation of Human Rights: THE CASE OF STREET CHILDREN IN GUATEMALA AND BRAZIL

Paloma Morais Correa

\section{Proteção Internacional dos Direitos Humanos e o Direito Brasileiro}

A LEI N. 11.340/06 E SUAS REPERCuSSõES No CONTRATO INDIVIDUAL DE TRABALHo. Humberto Lima de Lucena Filho e Waldeny Pereira Filho

ORIENTAÇÃo SEXUAL E DISCRIMINAÇão NO AMBIENTE LABORAL

Glaucia Fernanda Oliveira Martins Batalha

NORMAS EDITORIAIS 


\title{
O Processo e o Direito Coletivo no Sistema Interamericano de Direitos Humanos: uma análise com base na jurisprudência internacional
}

\author{
Coletive Right and Process in Interamerican \\ System of Human Rights: an analisys based on \\ the international jurisprudence*
}

Laercio Dias Franco Neto**

Dafne Fernandez de Bastos***

\section{Resumo}

O presente artigo visa apresentar como a Corte Interamericana de Direitos Humanos compreende o direito e o processo coletivo em sua jurisdição, em virtude da falta de instrumentos jurídicos taxativos no que concernem esses direito, e ao mesmo tempo, a obrigação de dar solução aos casos concretos à luz de uma maior proteção dos direitos humanos.

Palavras-chave: Direito Internacional dos Direitos Humanos. Corte Interamericana de Direitos Humanos. Direito e Processo Coletivo. Jurisprudência.

\section{Abstract}

The present article intends to establish how the Inter-American Court of Human Rights comprehends collective lawsuit and law in its jurisdiction, especially due do the lack of strong legal instruments about these rights, and still, the obligation to provide solutions to the cases aiming a wider protection on human rights.

Keywords: International Human Rights Law. Inter-American Court of Human Rights. Collective Lawsuit and Law. Jurisprudence.

* Recebido em 02/07/2013 Aprovado em 19/07/2013

** Mestrando em Direitos Humanos pela UFPA. Membro da Clínica de Direitos Humanos da Amazônia).

*** Mestre em Direitos Humanos pela UFPA. Especialista em Direito Público Rede Anhanguera-Uniderp).

\section{INTRODUÇÃo}

O surgimento do Direito Internacional, pelo menos enquanto expressão cunhada para se referir às relações jurídicas no plano mundial, é do século XVIII, do filósofo inglês Jeremy Bentham ${ }^{1}$, substituindo o equivalente da época, que tratava de um "direito das gentes". Apesar de consagrada na doutrina, na jurisprudência e na própria linguagem usual, é preciso retirar dessa expressão sua acepção correta, uma vez que o direito internacional difere em muito do direito interno ${ }^{2}$.

1 BENTHAM, Jeremy. "An Introduction to the Principles of Morals and Legislation", Clarendon Press, Oxford, 1996. P. 296.

2 Muito embora não seja o caso, é necessário apontar aqui, para fins didáticos, as correntes 
$\mathrm{O}$ aspecto mais relevante na diferenciação refere-se ao papel da política, simbiótico no direito internacional. Existia a percepção de que as relações internacionais e o direito internacional se confundiam, não sendo possível a efetivação deste sem o auxílio daquelas. A entender de forma diversa, a consequência seria o verdadeiro inadimplemento do direito internacinonal. Lafayete Rodrigues, jurista brasileiro do início do século XX, questionava-se ${ }^{3}$ :

\begin{abstract}
"Há quem pense que o direito internacional não seja senão um código de regras e máximas morais, a que as nações, na ausência de jurisdição superior incumbida de aplicá-lo e fazêe-lo observar, só prestarão obediência quando seus interesses o permitirem ou o exigirem, ou quando lhes faltar poder para impunemente viola1. Não haverá nisso uma parcela, uma partícula de verdade?"
\end{abstract}

No entanto, nos últimos noventa anos, percebe-se o estabelecimento de um Direito Internacional verdadeiramente autônomo, em parte devido ao processo de positivação das normas internacionais e do surgimento de caminho irreversível rumo à judicialização (surgimento de Tribunais Internacionais) e da consequente capacidade de justiciabilidade ${ }^{4}$ dos direitos perante esses órgãos.

Essa revolução no Direito Internacional deve-se

doutrinárias que apontam a relação entre o direito interno e o direito internacional. De fato, o direito internacional tem impacto direto no âmbito interno dos Estados. E, ainda que aqui se adote a teoria que os aponta como temáticas distintas, existem autores que dizem exatamente o oposto. Neste diapasão, tem-se a corrente doutrinária que prega o monismo, pela qual existiria apenas uma ordem jurídica, com normas internacionais e internas, interdependentes entre si. Esta corrente subdivide-se ainda em nacionalista - em que haveria primazia do direito interno de cada Estado - e internacionalista - sendo o ordenamento jurídico uno, o Direito das Gentes seria hierarquicamente superior. Os pensadores que defendem o dualismo, por sua vez, vinculam-se à teoria da incorporação ou teoria da mediatização - formulada por Paul Laband, estipula que é possível a regulação de relação de relações internas em um território de certo Estado por tratado, mas desde que ele seja incorporado por procedimento específico, passando então a ser norma interna - e entendem que o direito internacional e o direito interno são duas ordens diversas e não dependem em nada entre si, mas suas normas não poderiam entrar em conflito entre si; desta forma, o direito interno estaria restrito a regular a relação entre os indivíduos e o ente Estatal, ao passo que o direito internacional seria responsável por disciplinar as relações entre Estados.

3 PEREIRA, Lafayete Rodrigues. Princípios do Direito Internacional. J.R. dos Santos, Rio de Janeiro, 1902.

4 Apesar de tênue a diferença, não se pode olvidar a necessidade de trazer à análise o fato de que não existe sinonímia entre justiciabilidade $\mathrm{e}$ judicialização, muito embora os dois vocábulos sejam frequentemente utilizados com o mesmo significado. Conforme ensina Luiza Cristina Fonseca Frischeisen, na obra coletiva produzida pela Escola Superior do Ministério Público da União (Direitos Humanos Internacionais - Cap 8 \17: a justiciabilidade e a imposição dos direitos econômicos, sociais e culturais), a justiciabilidade traduz nada mais que uma mera potencialidade/possibilidade de judicialização, ao passo que esta última diz respeito à efetiva concretização destes direitos (sociais, econômicos, culturais) como objeto de demandas judiciais de forma intensa, o que já ocorre. também ao surgimento da dimensão de proteção dos direitos humanos no âmbito internacional, desdobrando-se em um ramo jurídico específico, o Direito Internacional dos Direitos Humanos, com autonomia didática, científica, estrutural próprios e que finalmente legitimou o cidadão não apenas como titular desses direitos, mas principalmente como titular em perquiri-lo ${ }^{5}$.

Ademais, apesar de não ser objeto constantemente trabalhado, faz-se imperioso observar que o direito não é unicamente material, mas também processual, apresentando os mecanismos de concreção das garantias materiais que prevê para os jurisdicionados.

E nesta seara, é inegável o surgimento - no plano internacional - de regras e procedimentos que irão definir a maneira em que se pode ter acesso às jurisdições internacionais e quais direitos poderão ser requeridos. Logo, pode-se atestar a existência de verdadeiro Direito Processual Internacional.

Este artigo possui um objeto restrito: cinge-se à discussão relativa à temática da proteção dos direitos humanos dentro do Sistema Interamericano de Direitos Humanos. Tem como objetivo específico desenvolver a questão dos meios processuais para efetivação dos direitos humanos de titularidade coletiva. Para ilustrar as conclusões e premissas aqui apresentadas, ilustra-se a explanação com exemplos colhidos da jurisprudência internacional.

Apesar deste corte metodológico, o trabalho não se furtará de analisar questões introdutórias que permitam o desenvolvimento apropriado do tema proposto, bem como tecerá digressões as mais completas possíveis acerca dos casos trazidos para exemplificação.

\section{Direitos Humanos e Processo Internacional}

\section{1 - Dimensão Internacional}

É costume afirmar que os direitos humanos surgiram no

5 A legitimação do indivíduo para a postulação internacional não é tema pacífico no ordenamento internacional. Desta forma, ainda não é garantida de forma plena a participação do indivíduo no que tange à postulação internacional, havendo tratamento diferenciado nos diversos sistemas (europeu, interamericano, etc). Entretanto, como este não é o tema central deste presente estudo e tecer comentários seria uma tergiversação muito grande, demandando obra própria para esta análise, contenta-se apenas em remeter o leitor à temática, a ser analisa com parcimônia na sistemática internacional. 
âmbito internacional apenas após a Segunda Guerra Mundial. Esta asserção, todavia, não é propriamente correta.

Em verdade, é possível observar-se a existência deste tão aclamado rol de direitos - os direitos humanos - e seus consectários necessários - os mecanismos de proteção - desde o século XIX, com a criação do Comitê Internacional da Cruz Vermelha, ou mesmo em 1919, com a Organização Internacional do Trabalho. Estes foram marcos no aparecimento de alguns mecanismos esparsos de proteção dos direitos da pessoa humana.

A partir de 1945, inicia-se um processo de sistematização internacional da proteção dos direitos humanos, tanto por uma vertente global, capitaneada pelas $\mathrm{Na}$ ções Unidas, materializada pelas Carta da ONU (1945) e pela Declaração Universal dos Direitos Humanos (1948), quanto pelas vertentes regionais de proteção.

A junção dessas duas vertentes propiciona a fundação de uma nova matéria jurídica, intitulada de Direito Internacional dos Direitos Humanos, que segundo palavras do juiz brasileiro da Corte Internacional de Justiça (CIJ) Antônio Augusto Cançado Trindade, seria o "corpus juris de salvaguarda do ser humano, conformado, no plano substantivo, por normas, princípios e conceitos elaborados e definidos em tratados e convenções, e resoluções de organismos internacionais. ${ }^{. "}$

Logo, o Direito Internacional dos Direitos Humanos é um ramo jurídico autônomo, com sua autonomia didática, estrutural legislativa o que permitiria uma existência principal e não acessória ao direito internacional.

É imperioso atentar que o direito internacional dos direitos humanos é o ramo jurídico que objetiva a proteção e a promoção da dignidade da pessoa humana no mundo inteiro, ou seja, em caráter universal. Fundamenta-se na premissa de que a dignidade humana deve ser resguardada não apenas pelo seu valor - que é inerente a qualquer ser humano -, mas também porque a paz, para ser mantida, exige o respeito aos direitos humanos.

Além dos direitos materiais, a "nova" ordem trouxe também as garantias necessárias à sua manutenção e proteção, com destaque aos mecanismos de ordem processual - objeto desde estudo.

6 CANÇADO TRINDADE, Antonio Augusto. Desafios e conquistas do Direito Internacional dos Direitos Humanos no início do século XXI. In: MEDEIROS, Antonio Paulo Cachapuz de (Org). Desafios do Direito Internacional contemporâneo. Brasília: Fundação Alexandre de Gusmão, 2007, p. 210.
O professor Guilherme de Assis Almeida indica o contexto desse acontecimento, o que permite a compreensão do motivo que explica o momento que desencadeou o desenvolvimento de um processo que já estava em curso:

"O Direito Internacional dos Direitos Humanos (DIDH)
foi elaborado no contexto histórico de dois eventos do
totalitarismo: os campos de concentração e o lançamento
das bombas atômicas de Hiroshima e Nagasaki, os
primeiros incidentes de uma guerra nuclear. Precisamente
nesse momento no qual as ideias-guias do passado estão
inadequadas para vincularem os seres humanos com o futuro
que surge o DIDH. Tendo isso em conta é que devemos
analisar o DIDH como uma tentativa de superação da
ruptura e uma resposta jurídica a esses eventos totalitários." 7

Os direitos humanos passaram a ser então protegidos; mais que isso, passaram a ser objeto de instrumentos jurídicos internacionais com força vinculante ${ }^{8}$, apesar de alguma impropriedade que eventualmente é apontada quando da interpretação dos direitos objeto de proteção em virtude da classificação doutrinária e jurisprudencial que lhes é conferida.

Ponto pacífico é que é característica inerente aos direitos humanos a indivisibilidade. A despeito disto, são comumente divididos em direitos de primeira, segunda e terceira dimensão (ou "geração", conforme criticada doutrina), o que ensejaria a noção de que seriam divisíveis.

Os direitos de primeira dimensão são os direitos civis e políticos, direitos de inspiração individual. Os direitos de segunda dimensão são os direitos sociais, econômicos e culturais. Por fim, os direitos de terceira dimensão são os direitos difusos e coletivos. Elísio Bastos afirma que os direitos humanos, como teoria que se conhece hoje, formaram um dos esteios jurídicos da Revolução Liberal. ${ }^{9}$

É empiricamente inegável que os ditos direitos de primeira dimensão foram aqueles que, ao longo dessa breve história contemporânea de proteção dos direitos

7 ALMEIDA, Guilherme de Assis. Soberania, Cosmopolitismo e Direito Internacional dos Direitos Humanos (DIDH). Disponível em http://www.nevusp.org/downloads/down075.pdf. Acesso em 12/02/2013, p. 11.

8 Como exemplo de instrumentos jurídicos internacionais vinculantes, tem-se o Pacto Internacional de Direitos Civis e Políticos de 1966, o Pacto Internacional de Direitos Sociais, Econômicos e Culturais de 1966, a Convenção Americana de Direitos Humanos de 1969, entre outros.

9 BASTOS, Elísio Augusto Velloso. Algumas reflexões sobre os Direitos Humanos e suas gerações. Revista dos Tribunais, ano 100, vol. 908, p. 174-201, junho 2011. 
humanos, tem possuído maior atenção e maior profundidade no que concerne a evolução dos mecanismos internacionais.

Paralelamente ao sistema global de proteção das $\mathrm{Na}$ ções Unidas, de cunho universalista, passaram a surgir também sistemas mais especializados, os ditos sistemas regionais de proteção. Trata-se de uma esquemas de promoção da dignidade humana que reúnem apenas alguns Estado, setorizadamente.

O objetivo primordial de tais sistemas regionais é o reforço da estrutura internacional para a proteção dos direitos humanos a partir da reunião de Estados que têm maiores afinidades entre si, em virtude de uma série de fatores; dentre eles a localização geográfica, os costumes, a cultura, etc.

São expoentes regionais os sistemas africano, interamericano e o europeu. Existe ainda esforços concentrados para a criação de um sistema asiático, mas trata-se de mecanismo ainda incipiente.

No continente americano, o sistema regional de proteção dos Direitos Humanos surgiu por meio da Organização dos Estados Americanos (OEA). Os primeiros instrumentos regionais que versavam sobre o tema foi o próprio Tratado Constitutivo da Organização (Carta da OEA), e posteriormente, a Declaração Americana de Direitos e Deveres do Homem ${ }^{10}$.

O sistema americano encontra-se, atualmente, bastante robustecido. Tem aparato normativo próprio e bem delineado, e tem atuação de repercussão, com destaque para as demandas indígenas/tribais, característica das Américas.

No sistema interamericano - real objeto do presente artigo -, convém apontar que o documento principal: a Convenção Americana de direitos humanos, peca da mesma forma que a europeia, somente versando sobre direitos de primeira dimensão (os civis e políticos), datando de 1969.

Os direitos sociais, culturais e econômicos, no entanto, não foram totalmente deixados de lado no âmbito do sistema interamericano, uma vez que em 1988, o Protocolo de San Salvador consagrou os direitos sociais, econômicos e culturais.

10 A Carta da OEA, instrumento que cria a Organização, assim como a Declaração Americana de Direitos e Deveres do Homem, foram adotadas em 1948, durante a realização da IX Conferência Internacional Americana realizada em Bogotá, Colômbia.
Ocorre que a restrição quanto à judicialização persevera, haja vista que a Convenção de 1969 está totalmente abrangida pela Corte Interamericana, enquanto apenas dois artigos do Protocolo Adicional (direito sociais, econômicos e culturais) são passíveis de reclamação jurisdicional.

A doutrina tradicional costuma imputar a estes grupos de direitos tratamento bastante diversificado em razão de os direitos civis e políticos supostamente possuírem natureza de prestação negativa, enquanto os direitos sociais, econômicos e culturais seriam de prestação positiva. Logo, estes últimos gerariam encargos ao Estado, em especial no âmbito orçamentário, o que não aconteceria com os primeiros.

O critério a que se refere esta classificação e consequente tratamento diverso diz respeito ao conteúdo das normas que veiculam direitos fundamentais. A partir dele, as normas constitucionais podem ser classificadas como de defesa ou prestacionais, conforme proposto por Víctor Abramovich e Christian Courtis ${ }^{11}$.

Para estes autores, direitos fundamentais de defesa seriam aqueles que se convenciona determinar como civis e políticos, ao passo que os direitos prestacionais seriam aqueles determinados como sociais, econômicos e culturais.

No primeiro grupo estariam abarcados os direitos civis e políticos - como a vida, a liberdade, a cidadania, etc - enquanto neste último seriam previstos direitos sociais, econômicos e culturais.

Hodiernamente, não se reputa possível subsistir tal dicotomia. A necessária prevalência dos direitos humanos, sua indivisibilidade, amparadas na premissa de que as normas devem ser interpretadas da maneira mais favorável possível à sua garantia fazem com que outra conclusão não seja a de que ambos os grupos de direitos poderão (e deverão), eventualmente, gerar despesa na sua implementação pelos Estados.

Ainda que os direitos de primeira dimensão - conforme a doutrina e a própria jurisprudência nacional e internacional costumam asseverar - exijam nada mais que uma mera abstenção por parte do Estado para que possam ser exercidos, é inegável que existe um valor econômico para que essa abstenção seja possível. É o

11 COURTIS, Cristian; ABRAMOVICH, Victor. Los derechos sociales como derechos exigibles. 2a ed. Madrid: Editorial Trotta S.A., 2002. 
que ocorre, por exemplo, com o exercício do poder político pelo povo nas eleições.

O voto exige que não haja intervenção do Poder Público, que deve se abster para que os cidadãos se manifestem livremente. Mas, para que essa manifestação possa ocorrer, é preciso que haja um sistema integrado e bem organizado para tal. Cita-se, como exemplo a existência de urnas, pessoal preparado (servidores públicos em sentido lato), poder judiciário organizado e especializado para solucionar eventuais controvérsias relativas à matéria eleitoral ou ao pleito em si, etc.

Portanto, faz-se necessário perquirir a fundamentalidade dos direitos, sejam eles de defesa, sejam sociais prestacionais.

Neste diapasão, os DESCs são dotados de eficácia jurídica, ainda que veiculados de maneira precípua em normas ditas programáticas. E a eles deve-se, portanto, ser atribuída efetividade.

Em um primeiro momento no sistema interamericano, considerando o processo de (re)democratização em muitos países, os direitos civis e políticos foram os principais vetores demandados pela sociedade, muito vezes frente ao novo Estado democrático, porém com instituições de certo resquício autoritário. Esse processo é marcante durante os anos 80 e os anos 90 do século XX.

Diante de um novo cenário continental, no qual a instabilidade política tornou-se acontecimento mais incomum (apesar de ainda presente em alguns Estados), a sociedade passou a clamar pelo atendimento a outros tipos de direitos (rectius direitos considerados sob outros aspectos).

Como demonstrado até agora, se é verdade que o DIDH representou evolução ímpar no Direito Internacional, inclusive concedendo ao indivíduo a possibilidade de ser sujeito ativo, a construção protetiva jurisdicional ocorreu em bases individuais. A dimensão coletiva foi sumariamente esquecida, sobretudo no que concerne aos procedimentos de reclamação jurisdicional.

Não é objetivo deste trabalho adentrar direitos de terceira dimensão, que apesar da terminologia de difusos e coletivos $^{12}$, não se confunde com a titularização coletiva pretendida. De fato, é possível falar em direitos coletivos titularizados individualmente e, por outro lado, da tutela coletiva de direitos ${ }^{13}$.

12 Ver art. 81, Código de Defesa do Consumidor Brasileiro.

13 Ver as lições de Daniel Amorim Assumpção Neves, na obra
A questão que delimita este estudo reveste-se de caráter processual frente às garantias já pacificadas no sistema interamericano de direitos humanos. Como já apontado que existe a dimensão da titularidade coletiva relativa aos direitos eminentemente civis (tutela coletiva de direitos), cujo maior exemplo é o direito à propriedade e o direito à reparação civil, sobretudo quando analisado à luz das relações peculiares das populações tradicionais e indígenas ainda existentes nas Américas, de forma geral.

Desta forma, ainda que seja verdade que a construção histórica de institutos coo a propriedade tenham ocorrido com base em acepções exclusivamente individuais, é preciso lidar com a verdade inexorável de que os direitos civis também são matéria que abarca inegavelmente uma dimensão coletiva.

Este o ponto central desta análise. Abordar-se-á também a tentativa de instrumentalização concernente aos direitos sociais, considerando que seu caráter coletivo é pressuposto para a própria consecução desses direitos.

\section{2 - Os instrumentos jurisdicionais do Sistema Interamericano}

O arcabouço normativo e institucional do Sistema Interamericano passou a contar com um órgão responsável "por promover o respeito e a defesa dos direitos humanos e servir como órgão consultivo da Organização em tal matéria" ${ }^{14}$.

A Comissão Interamericana de Direitos Humanos (CIDH) foi criada em 1959, por resolução da Quinta Reunião de Consulta dos Ministros das Relações Exteriores em Santiago, no Chile. A CIDH foi formalmente instalada em 1960, quando o Conselho da Organização aprovou seu Estatuto ${ }^{15}$.

Posteriormente, com a ulterior institucionalização de órgãos para o sistema, passou-se a contar com um tribunal internacional para o tema, denominado de Corte Interamericana de Direitos Humanos (CorteIDH), tendo sido criada em 1969 pela Convenção Americana de Direitos Humanos e instalada apenas em 1978, em São José, na Costa Rica ${ }^{16}$.

Manual de Processo Coletivo - volume único. Rio de Janeiro: Editora Método, 2012.

14 Artigo 106, da atual Carta da OEA.

15 HANASHIRO, Olaya Sílvia Machado Portella. O Sistema Interamericano de Proteção aos. Direitos Humanos. São Paulo: Edusp, 2001., p. 27.

16 RODRIGUES-PINZON, Diego; MARTIN, Claudia. La pro- 
Ambos os órgãos visam garantir o respeito aos documentos que integram seu escopo de atuação, basicamente positivações internacionais sobre Direitos Humanos.

Os principais documentos que compõem o Sistema são: a Convenção Americana de Direitos Humanos de 1969 (Pacto de San José da Costa Rica); o Protocolo Adicional à Convenção Americana sobre Direitos Humanos em matéria de Direitos Econômicos, Sociais e Culturais (Protocolo de San Salvador de 1988); a Convenção Interamericana para Prevenir, Punir e Erradicar a Violência contra a Mulher (Convenção de Belém do Pará); o Protocolo à Convenção Americana referente à Abolição da Pena de Morte ${ }^{17}$.

A Corte Interamericana de Direitos Humanos possui duas competências: consultiva, que abrange todos os Estados-partes da Convenção; e contenciosa, que demanda adesão expressa por parte dos países, e a qual vai interessar para o objeto deste artigo. Hodiernamente, dos trinta e cinco Estados que compõe o Sistema da Organização dos Estados Americanos, vinte e cinco reconhecem a jurisdição contenciosa da Corte.

A competência contenciosa é justamente a que possibilita ao indivíduo o acesso à Corte. No entanto, há de ressaltar-se que o acesso à jurisdição é indireto. Para alcançar o Tribunal, existe previamente uma espécie de juízo de admissibilidade e de tentativa conciliatória perante a Comissão Interamericana de Direitos Humanos, caracterizado como órgão quase judicial.

Para efeitos comparativos, no sistema europeu, desde 1994 com o advento do Protocolo XI, o acesso passou a ser direto à Corte de Estrasburgo, abolindo-se procedimento similar ao exigido no Sistema Interamericano.

Para que se possa apresentar uma petição perante a Comissão com o intuito de alcançar à Corte, é preciso que além da violação de um dispositivo expresso dos instrumentos internacionais que ela abarca e que o Estado violador reconheça sua competência, é fundamental que ainda sejam atendidos os seguintes requisitos: que hajam sido interpostos e esgotados os recursos da jurisdição interna, de acordo com os princípios de

hibición de la tortura y los malos tratos en el sistema interamericano: manual para víctimas y sus defensores. Genebra: Organização Mundial contra a tortura, 2006, p. 30-31.

17 O Brasil ratificou a Convenção Americana de Direitos Humanos em 1992; O Protocolo de San Salvador em 1996; a Convenção de Belém do Pará em1995; o Protocolo à Convenção Americana referente à Abolição da Pena de Morte em 1994. direito internacional geralmente reconhecidos; que seja apresentada dentro do prazo de seis meses, a partir da data em que o presumido prejudicado em seus direitos tenha sido notificado da decisão definitiva; e que a matéria da petição ou comunicação não esteja pendente de outro processo de solução internacional. ${ }^{18}$

Pode-se relativizar essas exigências quando não existir, na legislação interna do Estado de que se tratar, o devido processo legal para a proteção do direito ou direitos cujas violações estejam sendo alegadas; não se houver permitido ao presumido prejudicado em seus direitos o acesso aos recursos da jurisdição interna; ou houver sido impedido de esgotá-los, houver demora injustificada na decisão sobre os mencionados recursos. ${ }^{19}$

Vale ressaltar que não precisa ser a vítima a encaminhar a petição, mas basta que sejam representantes; desta forma, inclusive $\mathrm{ONG}^{\prime}$ s possuem a legitimidade necessária para postular perante a Comissão.

Anteriormente, com a eventual admissão da petição pela Comissão e encaminhamento à Corte, era a própria Comissão que iria atuar na etapa jurisdicional. Com a reforma do regulamento da Corte em 2010, passa a existir o acesso a essa fase judicial pelos representantes da vítima, significando expressiva aproximação da jurisdição efetiva aos sujeitos de direitos violados.

A Convenção Americana, em todo seu texto, sempre se refere como sujeitos de sua proteção "toda pessoa". $\mathrm{O}$ artigo 1.2 da CADH define a intenção do documento com essa expressão, dizendo que "pessoa é todo ser humano". Por uma perspectiva interpretativa literal, estaria reconhecido apenas o indivíduo como titular dos direitos albergados no texto convencional.

O objetivo do art. $1^{\circ} .2$ da CADH nunca foi evitar petições em nome de grupos, mas sim impedir que indivíduos sejam excluídos da proteção deste instrumento, sob a justificativa que não ostentam caráter de pessoa. ${ }^{20}$

No relatório da Comissão Interamericana sobre acesso à justiça em matéria de DESC (2007), algumas questões colocadas são extremamente relevantes, inclusive importantes críticas ao atual sistema. ${ }^{21}$

18 Convenção Americana de Direitos Humanos, 1969, art. 46.1. 19 Convenção Americana de Direitos Humanos, 1969, art. 46.2.

20 CHIRIBOGA, O. C. O Direito à Identidade Cultural dos Povos Indígenas e das Minorias Nacionais: um olhar a partir do Sistema Interamericano. SUR - Revista Internacional de Direitos Humanos. no 5, ano 3, 2006, p.47. 21 COMISSÃO INTERAMERICANA DE DIREITOS HUMANOS. 2007. El acesso a la justicia como garantia de los derechos económi- 
O direito material só pode ser garantido se houver um recurso processual efetivo e disponível para reclamá-lo, frente ao seu descumprimento. Ou seja, não é possível que o reconhecimento de cada vez mais direitos venha descompassado de uma inexistência processual garantidora.

Nesse ponto, destaca-se a imperiosidade da existência recursos judiciais de natureza coletiva e ações de classe em matéria de direitos sociais, já que atualmente, há imensa dificuldade em garantir a legitimação ativa desses grupos e uma participação efetiva nos procedimentos. A reforma do regulamento da Corte em 2010, já citada, pretendeu mitigar em parte essas dificuldades.

O relatório da Comissão sobre acesso à justiça destaca como exemplo a ser usado como inspiração os recursos processuais brasileiros, que permitiriam a fiscalização das políticas públicas por diversos atores sociais, em especial grupos ou comunidades afetadas por situações estruturais que mitigam seus direitos.

Citam-se as ações de amparo coletivo do direito processual brasileiro, como ação civil pública, mandado de segurança e outras, podendo em alguns casos a própria coletividade reclamar judicialmente seus direitos, ou em outros, legitimados representando essas classes.

Aponta o relatório que essa previsão processual brasileira contribuiu em muito para o avanço nos respeitos às garantias dos titulares de direitos, não só pela maneira mandamental repressiva, mas por meio da inclusão de alguns grupos no processo de discussão de políticas públicas.

A vigência de mecanismos adequados para reclamar os direitos, sejam sociais ou civis, especialmente na sua dimensão coletiva, é tema central a ser considerada na agenda de reformas judiciais dos países membros do Sistema Interamericano e também, no próprio âmago de proteção da Convenção Americana.

\section{A dimensão Coletiva NA JURISPRUdÊnCIA dA CORTE}

Como foi observado até então, do ponto de vista da sistematização normativa, o Sistema Interamericano carece de proteção específica da tutela coletiva. Contu-

cos, sociales y culturales. Estudio de los estándares fijados por el sistema interamericano de derechos humanos. OAS Doc. OEA/Ser.L/V/ 11.129, Doc. 4, 07 de setembro. do, umas das maneiras em que o Direito Internacional mais tem se desenvolvido nas últimas décadas ocorre por meio das decisões dos tribunais internacionais. $\mathrm{O}$ mesmo será percebido no presente caso.

\subsection{O Direito coletivo a terra}

O direito sobre a terra, mais especificamente o direito de propriedade é uma constante desde o início do mundo jurídico. A posse, maior expressão de poder sobre a terra e a propriedade, que com Napoleão Bonaparte e seu Code Civil adquiriu contornos quase absolutos, sempre foram motivo de celeumas entre particulares, entre entes públicos.

Ocorre que a percepção da terra não é a mesma por todos os povos que coabitam o planeta terra. Neste diapasão, é preciso deitar um olhar multiculturalista e eminentemente democrático, para conceber que, além do conceito clássico e ocidentalizado de propriedade (rectius direito sobre a terra) existe ainda a visão de povos que detém uma relação mais peculiar com este bem deveras valioso. Neste ínterim, cita-se as populações indígenas, tribais, além das comunidades tradicionais.

Considerando a existência de populações tradicionais e indígenas no contexto latino-americano, um tipo de demanda que passou a chegar à Corte se referia ao direito de propriedade e posse de terras ancestrais por esses povos. Nota-se que no caso, o direito material só será efetivamente protegido se o direito de propriedade puder ter uma noção coletiva. Não faria qualquer sentido o loteamento de uma terra ancestral e sua individualização para cada um dos sujeitos. Pelo contrário, para a maioria, dentro de uma cosmovisão específica, a unidade territorial é pressuposto para uma vida harmônica. $\mathrm{E}$ não poderia o Estado artificialmente individualizar para a satisfação de fins técnico-processuais. ${ }^{22}$

Quando essas demandas chegaram ao Sistema Interamericano, tanto Comissão, quanto Corte, não poderiam se furtar de oferecer uma resposta efetiva à situação. O primeiro julgado emblemático proferido pela Corte Interamericana foi do caso Comunidade Mayagna (Sumo) Awas Tingni v. Nicarágua.

22 CORTE INTERAMERICANA DE DIREITOS HUMANOS. 2001. Sentença de 31 de agosto, Comunidade Mayagna (Sumo) Awas Tingni v. Nicarágua, parágrafos 148 e 149. 
A Corte analisou no caso concreto qual seria o alcance do artigo 21 (direito à propriedade privada), entendendo que, por meio de uma interpretação extensiva, devia-se compreender como abarcada a proteção a uma propriedade coletiva de uma comunidade indígena. Para que seja efetivada essa titularidade coletiva, constitui pressuposto que o bem seja tratado como bem coletivo, e não mero agregado de bens individuais. ${ }^{23}$

Dessa forma, a Corte decidiu que ocorrera a violação do art. 21 (direito a propriedade) da Convenção Americana, reconhecendo, expressamente, que a dimensão de propriedade das comunidades indígenas diverge daquela literalmente expressa no texto da Convenção, possuindo, sobretudo, uma dimensão coletiva. Ainda assim, a Corte entendeu que ela estaria abarcada pela proteção do referido artigo. Aplicou-se uma interpretação extensiva, para maior proteção dos direitos.

Em voto separado dos Juízes Cançado Trindade, Máximo Gomes e Alirio Burelli, os magistrados asseveraram que: ${ }^{24}$

"A interpretação e a aplicação dadas pela Corte ao conteúdo normativo do art. 21 da Convenção Americana no presente caso da Comunidade Mayagna (Sumo) Awas Tingni v. Nicarágua representam, a nosso modo de ver, uma contribuição positiva a forma de proteção comunal da propriedade que prevalece entre os membros da dita comunidade." (tradução nossa)

No caso das Comunidades Indigenas Mayas do Distrito de Toledo v. Belize, a Comissão Interamericana, em seu relatório de admissibilidade à Corte, concluiu que "o direito de propriedade foi reconhecido como um dos direitos que contém esse aspecto coletivo.." (tradução nossa). ${ }^{25}$

Por meio da prática hermenêutica da Corte e da Comissão Interamericana, foi possível a ampliação da proteção da propriedade àqueles de titularidade coletiva, que mesmo sem expressão exata no texto convencional, não havia justificativa sob o aspecto dos direitos humanos que não fossem abarcados pela norma.

Segundo o autor Magnus Killander, em seu artigo

23 CORTE INTERAMERICANA DE DIREITOS HUMANOS. 2001. Sentença de 31 de agosto, Comunidade Mayagna (Sumo) Awas Tingni v. Nicarágua, parágrafos 148 e 149.

24 CORTE INTERAMERICANA DE DIREITOS HUMANOS. Sentença de 31 de agosto de 2001, Comunidade Mayagna (Sumo) Awas Tingni v. Nicarágua, Voto separado, parágrafo 15.

25 COMISSÃO INTERAMERICANA DE DIREITOS HUMANOS. Informe $n^{\circ} 40 / 04$, Caso 12.053, Comunidades Indígenas Mayas del Distrito de Toledo, Belize, 12 de outubro de 2004, parágrafo 113 . sobre a interpretação dos tratados regionais de direitos humanos, a interpretação tem sido feita acompanhando a evolução dos tempos e as condições atuais de vida, ou seja, considerando a Convenção Americana como um instrumento vivo. ${ }^{26}$

É devido a esse esforço hermenêutico da Corte, que segundo entendemos, que a sentença reconheceu a aplicação de um direito eminentemente civil (propriedade) com uma noção social/coletiva, como já vinha sendo esboçado nos casos anteriormente citados.

Inclusive, Jack Donnelly aponta em seu texto que, a divisão dos direitos humanos corresponde a uma certa artificialidade tendo em vista que, o direito a propriedade, que seria um direito social/coletivo, sempre foi tratado como direito civil, sem maiores explicações. ${ }^{27}$

O caso mais recente a ser julgado pela Corte Interamericana de Direitos Humanos sobre direito à propriedade coletiva é o da comunidade Xákmok Kásek v. Paraguai ${ }^{28}$.

O papel da Corte ao julgar esse caso transcendia a mera aplicação da Convenção. Valendo-se da equidade, que é um valor previsto tanto na Convenção Americana, quanto na Convenção de Viena sobre direitos dos tratados de 1969, dever-se-ia buscar a resposta correta para o caso concreto, considerando as especificidades presentes por se tratar de uma comunidade indígena e sua relação única e diferenciada com a terra.

A sentença do caso citado é de 2010. A Corte Interamericana já havia julgado casos semelhantes, especialmente no que concerne direito a propriedade ancestral por parte dos povos indígenas no contexto latino americano, o que mostra uma sequência lógica e de coerência nas decisões, o que permite a conclusão da consolidação desse entendimento pela Corte Interamericana.

\subsection{Garantia judicial e tutela judicial efetiva coletiva}

A Corte também desenvolveu outros mecanismos para robustecer a proteção dos direitos por uma perspectiva de titularidade coletiva, resguardando essa dimensão.

26 KILLANDER, Magnus. Interpretação dos tratados regionais de direitos humanos. SURRevista Internacional de Direitos Humanos, São Paulo, v. 7, n. 13, dez/2010.

27 DONNELLY, Jack. Universal buman rights in theory and practice. 2.ed. Londres: Cornell University, 2003. p. 7-52

28 CORTE INTERAMERICANA DE DIREITOS HUMANOS. Sentença de 17 de junho de 2005, Comunidade Indígena Yakye Axa v. Paraguai. 
Em outro caso paradigmático, Yakye Axa v. Paragua $^{29}$, a Corte condenou o Estado paraguaio, entre outras violações, pelo descumprimento do artigo $8^{\circ}$ (garantias judiciais) e artigo $25^{\circ}$ (proteção judicial).

O caso, semelhante ao Awas Tigni v. Nicarágua, também versava sobre o direito coletivo à propriedade ancestral da comunidade indígena Yakye Axa. Contudo, em sua sentença, o Estado também foi condenado por não prover à comunidade e seus membros recurso efetivo e eficaz para atender aos anseios da população em questão.

Nota-se que, ao se configurarem violados os artigos $8^{\circ}$ e $25^{\circ}$, garantias judicias e tutela judicial efetiva, o problema foi a ausência de mecanismos coletivos no Estado paraguaio para que os indígenas pudessem reclamar seus direitos. Ou seja, reconhece-se que há a necessidade de instrumentos processuais que possam garantir o respeito efetivo ao direito coletivo.

A corte ordenou que o Paraguai adotasse medidas internas que criassem um mecanismo judicial efetivo, como medida de satisfação e garantia de não repetição. O direito internacional, à medida que o Estado transferiu à Corte parte de sua soberania, impõe ao Paraguai a necessidade de internamente instrumentalizar mecanismos efetivos que garantam a tutela coletiva, no caso presente, de uma parcela específica da população. Ademais, não basta que haja um direito se ele não é protegido na prática. A previsão interna não pode ser mera alegoria.

\subsection{A (não) individualização das vítimas para fins de reparação civil}

Historicamente, a Corte Interamericana de Direitos Humanos, nas suas sentenças, quando declara a violação de direitos, mesmo esses que tem sido trabalhado ao longo desse artigo que versam sobre titularidade coletiva, o faz somente em relação aos membros da comunidade, sendo mandatória a individualização dos lesionados, e não a lesão contra as comunidades per se. É pressuposto, como visto nos casos Massacres de Ituango v. Colômbia ${ }^{30} \mathrm{e}$ Awas Tingni v Nicarágua, a necessidade de nominação expressa e individual dos eventuais beneficiários.

29 CORTE INTERAMERICANA DE DIREITOS HUMANOS. Sentença de 17 de junho de 2005, Comunidade Indígena Yakye Axa v. Paraguai.

30 CORTE INTERAMERICANA DE DIREITOS HUMANOS. Sentença de 01 de julho de 2006, Massacres de Ituango v.Colômbia.
Em um paralelo ao direito brasileiro, seria afirmar que, nos casos citados que versam sobre direitos de titularidade dos povos indígenas ou tradicionais, cuja dimensão é indubitavelmente coletiva, no momento da reparação civil e da própria configuração da lesão, ele seria individual homogêneo.

Essa interpretação se deve novamente ao famigerado artigo 1.2 da Convenção, que define como indivíduo o ser humano, titular de direitos e liberdades, sem menção expressa de caráter coletivo.

Esse método interpretativo pode acabar por violar outros direitos ao ignorar a própria cosmovisão desses povos, que eventualmente integrem a comunidade, e que por força da sentença judicial, sejam excluídas pela decisão da Corte.

Contudo, em um caso isolado, e dotado de peculiaridades, a Corte já decidiu de forma diferente, que, contudo, não necessariamente significa uma mudança de entendimento para casos futuros.

O caso aludido é o do Povo Saramaka v. Suriname ${ }^{31}$, que devido às especificidades do povo Saramaka, composto por mais de trinta mil pessoas dispersas na região superior do rio Suriname, do distrito Brokopondo e outras áreas do Estado, inclusive na capital, Paramaribo, dispensou-se a individualização e nominação dos indivíduos, mas manteve-se como parte lesionada "os membros" da comunidade Saramaka, e não ela per se.

Ainda que a sentença, nesse aspecto, não tenha sido, pelo aspecto da dimensão coletiva, satisfatório, nas medidas de indenização, a Corte contemplou em parte essa diretriz.

No que concerne dano material, a Corte ordenou a indenização no valor de 75 mil dólares a favor do povo Saramaka pela concessão estatal para extração de madeira em suas terras.

A Corte também reconheceu um dano imaterial pelo dano ambiental e danos à propriedade, não somente no que concerne a subsistência do povo, mas também o aspecto espiritual da cosmovisão deles com a terra. Para ressarcir tal dano, a Corte ordenou que o Estado criasse um fundo em prol dos membros da comunidade e depositasse 600 mil dólares (além dos 75 mil dólares

31 CORTE INTERAMERICANA DE DIREITOS HUMANOS. Sentença de 28 de novembro de 2007, Povo Saramaka v. Suriname. 
referentes ao dano material), com o intuito de financiar projetos educativos, de agricultura, entre outros.

Por mais que haja uma relutância técnico-processual na Corte em considerar às comunidades per se, como no caso dos Saramaka, insistindo-se na individualização e nominação, ou no caso presente, referindo-se aos "membros da comunidade", o que se observa é que a decisão foi de proferida de forma a atender a dimensão coletiva do direito, nesse caso, o da reparação civil.

Não foram apenas alguns membros da comunidade Saramaka que foram contemplados. Veja-se que, mesmo membros que vivem em território não necessariamente atingido pelo dano material, ainda assim são beneficiários, enquanto coletividade, das reparações. Apesar da relutância em pronunciar expressamente, a Corte Interamericana de fato reconheceu essa dimensão coletiva, ressalvando-se as peculiaridades dos Saramaka.

Um ponto que preocupa é que a fundamentação legal da criação do fundo e as indenizações coletivas ocorreram com base na equidade. Ainda que esse método de decisão judicial seja perfeitamente reconhecido no direito internacional, não se pode relegar a esse mecanismo, que deve ser utilizado subsidiariamente, com a intenção de evitar a não resolução de casos e sempre em busca da justiça, a solução para o problema.

A dimensão coletiva, por sua própria importância, merece instrumento assecuratório claro e bem definido, ou então, que com bases hermenêuticas conferindo significado mais completo ao artigo 1.2. O uso da equidade, apesar de adequado e satisfatório no caso concreto, relegaria insegurança jurídica às situações futuras.

Outro caso em que a equidade foi utilizada para justificar a concessão de reparação civil sem a individualização das vítimas foi a do caso Xákmok Kásek v. Paraguai. A Corte determinou que fosse disponibilizado aos líderes da comunidade indígena determinado valor em pecúnia para que de acordo com os costumes da comunidade colocassem a disposição de cada família que teve o dano sofrido o valor necessário.

É interessante notar que, essa decisão da Corte foi tomada com base na equidade. Porém, ela respeitou justamente a sensibilidade jurídica dos Xákmok Kásek, pois não há outro mais adequado do que a própria comunidade para mensurar o dano individual de cada membro.

Deveriam os precedentes dos casos das comunidades Saramaka e Xákmok Kásek servir como fundamen- to a ser repetido no futuro, não apenas no que concerne direitos dos povos indígenas, mas também nos direitos que se referem à titularidade coletiva em geral.

\section{Considerações finais}

Ao longo deste trabalho, dois tipos diferentes de direitos foram abordados, quais sejam: os direitos civis e os direitos sociais. Tocou-se sempre na temática destes direitos a partir da ótica de sua titularidade, evidenciando-se que, além da concepção tradicional que vê a titularidade individual, existe também a noção coletiva da titularidade destes direitos.

Os direitos sociais carecem de uma maior instrumentalização jurisdicional, tanto no Sistema Interamericano, como no Sistema Europeu. Os motivos dessa restrição ocorrem em parte pela interpretação de que a implementação desses direitos teria um custo muito alto, e que seria função do Estado, por meio de políticas públicas, decidir como implementá-las, e não um tribunal internacional. Ainda assim, é inegável que os direitos sociais para serem efetivados precisam ser considerados sob seu aspecto coletivo.

Já em relação aos direitos civis, em especial, à propriedade, a Corte Interamericana já teve a oportunidade, em diversas vezes, de decidir em relação a dimensão coletiva dos mesmos, especialmente no que concerne a titularidade coletiva de povos indígenas, tribais ou tradicionais.

É inegável o avanço que a jurisprudência da Corte tem alcançado, não somente em relação às próprias decisões judiciais, mas como fonte criadora do direito internacional. Ainda há muito que pode ser evoluído, mas o caminho parece traçado.

$\mathrm{Na}$ atual fase do direito internacional dos direitos humanos - DIDH -, em especial em relação aos Sistemas Regionais de proteção, o direito material abarcado é notadamente avançado. No Sistema Interamericano, por exemplo, além da Convenção Americana e o Protocolo Adicional sobre direitos sociais, econômicos e culturais, existem uma série de outros tratados sobre temas específicos, seja a prevenção, punição e erradicação da violência contra a mulher (Convenção de Belém do Pará), Protocolo referente à abolição da pena de morte, entre outros.

O que se identifica como carente ainda, de acordo com o próprio relatório sobre acesso a justiça, são os 
instrumentos processuais que garantiriam ao cidadão a possibilidade de efetivar esses direitos. Não se pode pensar no processo, como outrora, apenas como um instrumento formal, mas sim como meio para a implementação dos direitos conquistados e normatizados.

A análise de alguns dos casos citados demonstrou, entre outras coisas, como o tema possui uma interdisciplinaridade necessária. Se a decisão do caso tivesse sido tomada apenas em bases legalistas, negando o caráter especial das comunidades indígenas, não estaria se fazendo justiça. Nesse ponto, a participação da antropologia, talvez até de maneira despropositada pela Corte, concedeu outro viés para a solução do caso.

O reconhecimento das sensibilidades jurídicas, numa verdadeira aplicação prática do ir e vir hermenêutico preconizado por Geertz, mostrou de que forma antropologia e direito se comunicam. Indubitavelmente, o direito internacional se mostrou instrumento que permitiu esse tipo de interpretação construtiva.

Não há efetivação do direito material sem os instrumentos processuais adequados. O Direito Internacional dos Direitos Humanos é normativo e aplicável, e não apenas um conjunto de valores que nortearão o comportamento dos Estados. O que está previsto, precisa ser cumprido. E a melhor maneira para atingir esse objetivo é instrumentalizando o cidadão com os meios processuais mais efetivos.

\section{REFERÊNCIAS}

BASTOS, Dafne Fernandez de. A aplicabilidade imediata dos direitos sociais prestacionais: análise da norma do artigo $5^{\circ}, \$ 1^{\circ}$ da constituição federal de 1988. Trabalho de conclusão de curso - Pós Graduação (manuscrito).

BASTOS, Elísio Augusto Velloso. Algumas reflexões sobre os Direitos Humanos e suas gerações. Revista dos tribunais, ano 100, vol. 908, p. 174-201, junho 2011.

BENTHAM, Jeremy. "An Introduction to the Principles of Morals and Legislation". Clarendon Press, Oxford, 1996.

BOBBIO, Norberto. A era dos direitos. Trad. Carlos Nelson Coutinho; apres. Celso Lafer. Rio de Janeiro: Elsevier, $200-10^{a}$ reimp.
CHIRIBOGA, O. C. O Direito à Identidade Cultural dos Povos Indígenas e das Minorias Nacionais: um olhar a partir do Sistema Interamericano. SUR Revista Internacional de Direitos Humanos. $n^{\circ}$, ano 3, 2006.

COMISSÃO INTERAMERICANA DE DIREITOS HUMANOS. El acesso a la justicia como garantia de los derechos económicos, sociales y culturales. Estudio de los estándares fijados por el sistema interamericano de derechos humanos. OAS Doc. OEA/ Ser.L/V/11.129, Doc. 4, 07 de setembro de 2007.

Informe $\mathrm{n}^{\circ} 40 / 04$, Caso

12.053, Comunidades Indígenas Mayas del Distrito de Toledo, Belize, 12 de outubro de 2004.

CONVENÇÃO AMERICANA SOBRE DIREITOS HUMANOS. Conferência

Especializada Interamericana sobre Direitos Humanos. São José da Costa Rica, 1969.

CORTE INTERAMERICANA DE DIREITOS HUMANOS. Caso Comunidade IndígenaYakye Axa vs. Paraguai. Sentença de mérito, de 17 de junho de 2005. Série $C, n^{\circ} 125$.

Caso Massacres de Ituango v. Colômbia. Sentença de mérito 01 de julho de 2006. Série $C, n^{\circ} 148$.

Caso Comunidade Mayagna (Sumo) Awas Tingni vs. Nicarágua Sentença de mérito, reparações e custas, de 31 de agosto de 2001. Série $C, n^{\circ} 79$.

Caso Povo Saramaka vs.

Suriname. Sentença de mérito, de 28 de novembro de 2007. Série $\mathrm{C}, \mathrm{n}^{\circ} 172$.

Regulamento da Corte

Interamericana de Direitos Humanos. Aprovado em novembro de 2009.

COURTIS, Cristian; ABRAMOVICH, Victor. Los derechos sociales como derechos exigibles. $2 \mathrm{a}$ ed. Madrid: Editorial Trotta S.A., 2002.

DONNELLY, Jack. Universal human rights in theory and practice. 2.ed. Londres: Cornell University, 2003.

ESCOLA SUPERIOR DO MINISTÉRIO PÚBLICO DA UNIÃO. Manual prático de direitos humanos internacionais. Coord. Sven Peterke; Colab. André Ramos de Carvalho et al. Brasília: ESMPU, 2009. 
FLORES, Joaquín Herrera. A reinvenção dos direitos humanos. Trad. Carlos Roberto Diogo Garcia; Antônio Henrique Graciano Suxberger; Jefferson Aparecido Dias. Florianópolis: Fundação Boiteux, 2009.

GEERTZ, Clifford. "O saber local: fatos e leis em uma perspectiva comparativa" In O saber local: novos ensaios de Antropologia interpretativa. Rio de Janeiro, Vozes, 1998: 249-356.

HANASHIRO, Olaya Sillvia Machado Portella. O Sistema Interamericano de Proteção aos. Direitos Humanos. São Paulo: Edusp, 2001.

KILLANDER, Magnus. Interpretação dos tratados regionais de direitos humanos. SURRevista Internacional de Direitos Humanos, São Paulo, v. 7, n. 13, dez/2010.

NEVES, Daniel Amorim Assumpção. Manual de processo coletivo - volume único. Rio de Janeiro: Editora Método, 2012.

PEREIRA, Lafayete Rodrigues. Princípios do Direito Internacional. J.R. dos Santos, Rio de Janeiro, 1902.

PIOVESAN, Flávia. Direito Internacional dos direitos humanos e o direito brasileiro: hierarquia dos tratados de direitos humanos à luz da constituição brasileira. Leituras complementares de constitucional: direi- tos humanos e direitos fundamentais. (org,) Marcelo Novelino. $4^{a}$ ed. amp. rev. e atual. Salvador: Editora Juspodivm, 2010. p. 43-69.

PORTELA, Paulo Henrique Gonçalves. Direito internacional público e privado. $4^{a}$ ed., rev., amp. e atual. Salvador: Editora Juspodivm, 2012. Leituras complementares de constitucional: direitos humanos e direitos fundamentais. (org,) Marcelo Novelino. $4^{\mathrm{a}}$ ed. amp. rev. e atual. Salvador: Editora Juspodivm, 2010. p. $71-96$.

RODRIGUES-PINZON, Diego; MARTIN, Claudia. La prohibición de la tortura y los malos tratos en el sistema interamericano: manual para víctimas y sus defensores. Genebra: Organização Mundial contra a tortura, 2006

SARLET, Ingo Wolfgang. Algumas notas sobre os direitos fundamentais e os tratados internacionais em matéria de direitos humanos.

SEN, Amartya. Desenvolvimento como liberdade. Trad. Laura Teixeira Motta; rev. téc. Ricardo Doninnelli Mendes. São Paulo: Companhia das Letras, 2010.

SUR. Revista Internacional de Direitos Humanos Rede universitária de Direitos Humanos. V. 1, n. 1, jan. 2004. São Paulo, 2004. 
Para publicar na Revista de Direito Internacional, acesse o endereço eletrônico www.rdi.uniceub.br ou www.brazilianjournal.org.

Observe as normas de publicação, para facilitar e agilizar o trabalho de edição. 